\title{
Mental Health Literacy among Family Caregivers of Schizophrenia Patients
}

\author{
Mohamad, M. S. ${ }^{1}$, Zabidah, P. ${ }^{2}$, Fauziah, I. ${ }^{1}$ \& Sarnon, N. ${ }^{1}$ \\ ${ }^{1}$ School of Psychology and Human Development, Faculty of Social Sciences and Humanities, Universiti \\ Kebangsaan Malaysia, Bangi, Malaysia \\ ${ }^{2}$ Department of Nursing, Faculty of Medicine \& Health Science, Universiti Malaysia Sarawak, Kuching, \\ Malaysia
}

Correspondence: Mohamad, M. S., School of Psychology and Human Development, Faculty of Social Sciences and Humanities, Universiti Kebangsaan Malaysia, 43600 UKM Bangi, Selangor, Malaysia. Tel: 60-3-8921-3655. E-mail: msuhaimi@ukm.my

Received: June 4, 2012

Accepted: June 16, 2012 Published: July 16, 2012

doi:10.5539/ass.v8n9p74

URL: http://dx.doi.org/10.5539/ass.v8n9p74

\begin{abstract}
The benefits of public knowledge towards physical health are widely accepted but the area of mental health literacy remains undervalued and relatively neglected. The study aimed to identify caregivers' mental health literacy in Malaysia. There were 154 family caregivers participated in the face-to-face semi-structured interview regarding their personal caring experiences. This study found that majority of the caregivers was women aged less than 60 years. Most of the caregivers have some understanding about their relatives' mental illness. More than half of the participants found that the doctors were considered as their primary source of information about mental health. Consistent with previous literature in Malaysia, most of the caregivers used religious and traditional coping mechanism in their help-seeking processes. Each ethnic group had their own strong cultural beliefs about mental illness. The implications for mental health services are that many of the caregivers need help to educate their family members about mental illness. While this study emphasized on the family members who should be targeted to improve mental health literacy it also become significant to the public to reduce stigma towards the person with mental illness and their family.
\end{abstract}

Keywords: mental health literacy, family, caregiver, schizophrenia, Malaysian

\section{Introduction}

Advancements in information technology and medical technology stimulate the capacity of the public to be better informed and educated about the nature of many diseases and illness. The core of this capacity is the concept of health literacy. DeWalt et al. (2004) defined health literacy as both the ability to read, write, and comprehend word or phrases and the ability to use health and medical knowledge to promote and maintain physical health. Many countries include an objective to improve health literacy as one of the agendas for their Health Communication Report (Nutbeam and Kickbusch, 2000). The field of health literacy has advanced since the 2004 but health literacy in developing countries still remains poor and unresolved (Ganasen et al., 2008). What is more alarming is that the health literacy issues are worsening in developing countries especially in the component of mental health.

People with mental illness and their families struggle throughout their life by being stigmatised by the public prejudices and stereotyping against mental illness. Cohen et al. (2002) suggests that the public have the mistaken beliefs that mental illnesses are not real and disabling conditions and hence it discourages people from seeking care. As a result, mental health efforts do not receive equivalent resources as those of other health problems (Cohen et al., 2002). This is also demonstrated in public knowledge when the importance of health literacy for physical health is widely acknowledged but the area of mental health literacy has been comparatively neglected. Furnham et al. (2011) reported that most of the literature found that mental health literacy among the general public is lamentably poor. 
Jorm (2000) defined mental health literacy as "knowledge and beliefs about mental disorders which aid their recognition, management or prevention". Mental health literacy consists of several components, including: (a) the ability to recognise specific disorders or different types of psychological distress; (b) knowledge and beliefs about risk factors and causes; (c) knowledge and beliefs about self-help interventions; (d) knowledge and beliefs about the professional help available; (e) attitudes which facilitate recognition and appropriate help-seeking; and (f) knowledge of how to seek mental health information (Jorm et al., 1997). Meanwhile, Lauber et al. (2003) defined mental health literacy as knowledge and beliefs about mental disorders coupled with the ability to access, understand and use information to recognize and manage disorders.

In Western countries, schizophrenia, the most common of mental illness is often seen by the public as caused by the social environment, particularly recent stressors (Dietrich et al., 2004; Angermeyer et al., 2005; Jorm et al., 1997; Link et al., 1999). While psychiatric epidemiologists would concur on the importance of stressful life events in depression, life events are probably more of a trigger than a cause in schizophrenia. Biological factors are seen by the public as less important than environmental ones (Matschinger and Angermeyer, 1996; Wolff et al., 1996; Jorm et al., 1997; Link et al., 1999), although relatives of people with schizophrenia are more likely to see biological factors as important (Angermeyer and Matschinger, 1996a). Providing the label 'schizophrenia' to a vignette has also been found to increase the likelihood that biological rather than psychosocial causes are seen as responsible (Angermeyer and Matschinger, 1996b). In some Eastern cultures, supernatural phenomena, such as witchcraft and possession by evil spirits, are seen as important causes of mental disorders (Razali et al., 1996). However, this phenomenon is uncommon in the West (Angermeyer et al., 1999; Brändli, 1999).

Beliefs about causes and effects may alter patterns of help seeking and response to treatment. In Malaysia, beliefs about mental illness as supernatural causes are particularly associated with a greater use of traditional healers and poorer compliance with medication (Razali and Yassin, 2008; Razali et al., 1996). In a US controlled trial of psychotherapy for depression, belief in relationship causes was associated with a better outcome in behavioural therapy, while belief in existential causes was associated with a better outcome in cognitive therapy (Addis and Jacobson, 1996).

Our knowledge about mental health literacy amongst family caregivers is inadequately addressed in the Malaysian context. There is no study done regarding the mental health literacy of caregivers of people with mental health problems yet the number of people with mental health problem is on the rise. Therefore, this study was conducted with the aim of identifying caregivers' mental health literacy in Malaysia.

\section{Materials and Method}

\subsection{Research Design}

This study adopted qualitative method in order to identify the cognitive appraisal of mental health. The participants in this study were Malay, Chinese and Indian caregivers who were living in rural and urban areas. They were those who sought community mental health treatments for their patients in three community clinics in the Northern states of Peninsular Malaysia. A formal ethical approval and administrative clearance was obtained from the National Medical Research Register, Ministry of Health of Malaysia. In addition, a written informed consent was obtained from each participant. Subsequently, the participants were given a choice to select the interview site based on their convenience whether in their homes or in the community clinics. The interview that was tape recorded took approximately 45 to 60 minutes. Additional inclusion criteria for recruitment of participants included: (1) aged above 18 years old, (2) main caregivers, (3) more than 6 months caring for mentally patients, and (4) possessed the ability to express themselves clearly in Malay and English languages.

\subsection{Respondents}

Twenty-four family caregivers volunteered to participate in the study. Two thirds were Malays, with six Chinese and two Indians. Most of the Malays lived in the rural area and all but one of the Chinese lived in the urban area. The caregivers were recruited equally from both the urban and rural areas. More female (14) than male (10) caregivers were interviewed. Most were parents with two thirds being mothers. An equal number of husbands and wives were recruited in this study. There were five siblings, two brothers and three sisters of schizophrenic patients. Most of the caregivers were aged 50 years old and above. Only one of the caregivers was younger, below 40 years old. These participants had adequate experienced in providing care to their family ranging from one year to more than 20 years. The average of caring duration was 12 years. The participants were recruited from the community clinics that offered community mental health services. Most of them had used the community mental health services for almost five years. The most frequent service used was adult day care in the psychosocial rehabilitation centre. 


\subsection{Data Collection}

This study used a semi-structured interview because it followed a less rigid format with open-ended questions to elicit more qualitative information. Barriball and While (1994) suggested that a semi-structured interview is an efficient technique to obtain information from people who have limited time available for an interview and allows the researcher to make sure the "key issues" are covered. The researcher conducted semi-structured interviews with the main carers. The main carer was defined as the family member who spends most of the time with the relative and it must be proven by the relative as being one without whom the relative would be able to maintain their position living in the community. The semi-structured interview enables exploration of the mental health literacy from the carers' perspectives with respect of their caring roles to people with mental illness in their home setting. The focus of each interview was to learn the caregiver's experience about their knowledge, perception and beliefs about mental health. The first part of the question was "what kind of the mental health services did they found helpful for caregivers". The second part of the questionnaire was for the caregivers to describe the knowledge they have had and they were asked to explain what their beliefs about mental health were. Follow-up questions were used to encourage participants to explain more fully or to clarify meanings of participant's responses. The interviews concluded with the question about their help seeking process in caring for a relative with mental illness. Data collection stopped when the researcher noted data reached saturation point in which there was no new information about the use of community mental health services.

\subsection{Data Analysis}

Each of the tape recorded interviews was transcribed. Then the researcher reviewed the transcripts again while listening to the tapes to make sure that the interview content was complete. A second reading of the transcripts was done to obtain a general impression of the caregivers' knowledge and beliefs about mental health. The data analysis was conducted using the Nvivo where the free nodes emerged. Later, all emerging nodes were clustered under the tree nodes. The framework analysis suggested by Ritchie and Lewis (2003) was applied. There were five stages of framework analysis:

1). Familiarisation with data (becoming thoroughly immersed in the material collected)

2). Indexing data (labelling key issues that emerged across a set of data)

3). Devising a series of thematic charts (allowing the full pattern across a set of data to be explored and reviewed)

4). Mapping and interpreting data (looking for associations, providing explanations, highlighting key characteristics and ideas)

5). Developing a thematic framework (identifying key issues from data)

The same framework was used to map the themes and sub-themes into different groups such as urban versus rural and Malay versus non-Malay to see the similarities and differences between the caregivers' answers. Later, the two main themes of knowledge and beliefs were further examined using the above frameworks to identify categories and patterns in caregivers' responses. Verbatim quotes from the participants were selected to illustrate the identified themes and categories. The frequency of themes emerged was also recorded to see which issue or idea was commonly discussed by caregivers.

\section{Results}

\subsection{Knowledge about Mental Illness}

The majority of the caregivers described that they learn about mental illness from the doctors and nurses. They further gather their knowledge and information about mental illness through readings. These awareness and understandings make the caregivers accepted the mental health services as rendered and enhance their skills in handling their relatives, particularly in medication compliance. Their opportunity to join the support groups was reported as worthy in further understanding and support for the family with mental illness.

\subsection{Sources of Information}

Most of the carers who use the mental health services claimed that they learned about mental illness from the mental health professionals. Generally, the carers begin seeking and gaining knowledge about their relatives' mental illness through the information given by the doctors who treat their relatives. These doctors are considered as their primary source of information, the first person to inform the carers about their relatives' diagnosis when treated at the hospitals. It is no wonder that carers fully rely on information provided during consultation from the doctors regarding their relatives' health issues. Caregivers who have been educated in a Western model of mental illness have more knowledge concerning the medical model. For instance, a husband 
who graduated from overseas stated that he knew about his wife's illness through their family doctor and acknowledged that they have a good rapport with the doctor. Consequently, another carer who graduated from a Western University expanded his knowledge about mental illness by browsing the internet.

Some of the carers demonstrated other means of obtaining information about mental illness such as through reading books, magazines and newspapers. As an example, a Chinese mother recounted that she came across new medication to treat her child whilst reading the health magazine and shared the information with the doctor. They indicated that the media also made contributions to mental illness education, including one caregiver who acknowledged that he improved his knowledge about schizophrenia through reading the newspapers and magazines. In addition, some of the carers recounted that they had gained a better understanding about mental illness following the psycho-education programme conducted by the staff nurses. For example, a mother explains,

"After talking to the doctor I understood about his mental problems. Yes, indeed the doctor explained about his mental illness and his need for medication, but I know more about his situation and how to handle him through the psycho-education programmes conducted by the staff nurses who visited my house."

\subsection{Causes and Effects of Mental Illness}

Generally, two main factors were identified by the carers when asked about the causal factors of mental illness. These factors are internal and external factors. For instance, some of the carers considered their relatives' mental illness as genetic. One of the carers believed that his relative developed mental illness because there were other family members who experienced similar mental health problems. He said that "this is a heredity [genetic] illness because on my ex-wife's family side, there are a few relatives that I know who have mental problems."

Another male carer who had two siblings with schizophrenia also deduced that the mental illness is in the family. He recounted that schizophrenia was in the family genes and that might be why two of his siblings suffered schizophrenia as well:

"My younger sister started to be sick when she was 17 years old whereas my brother got it at the age of 27. Now both of them are diagnosed with schizophrenia. There might be a possibility of genetic factors because two of my family members have the same illness. I know that one of my aunties is mentally ill."

It is noted that the carers perceived their relatives' mental illness as genetically linked because more than one family member were known to suffer from mental illness. They considered the cause of the mental illness as genetic, which was conceptualised as an internal factor. On the other hand some of the carers mentioned external factors as being the cause of mental illness. These factors include depression, traumatic events and domestic violence. For instance, one of the caregivers recounted that his relative started to suffer from depression because of burnout at work and later was diagnosed as schizophrenia.

Some of the carers suggested that their relatives were depressed and that their mental illness was due to problems encountered in their relationship. For example, an Indian mother disclosed that her son started to become depressed after a break-up with his girl friend and has lost social network as well as burnout at work. Similarly, a Malay mother also reported that her daughter became depressed after being heartbroken and, consequently, the relative lost her jobs. She also explained about her daughter's permanent disability as her daughter was suffering from paraplegia. Some carers relate their relatives' mental illness to traumatic events they encountered. These carers described that their relatives repeatedly experienced traumatic events in their life. For instance, a husband explained that his wife's illness might be caused by the depression after giving birth to a daughter who died but he also believed that it might be due to supernatural factors:

"I remember that my wife started to become sick after giving birth to our first daughter. She became depressed after the child died. My in-laws said that she was 'gila meroyan' (postpartum psychosis) and when I asked the doctor, she told me it might be possible with the family history. However, I'm still not sure about the real cause of her illness. It might be something else within the family history that cannot be explained like mystical things."

Another carer who was a mother reported that she suspected that her daughter developed mentally illness after a serious car accident and being traumatised by several failed marriages. There was also a mother who suspected that her own marital problems had caused the mental illness. She claimed that her youngest son became depressed after experiencing domestic violence since his childhood. She seemed to accept her son's illness and blamed on her failed marriage. However, two carers denied that their relatives have mental illness after seeking 
the doctors' treatment. They believed that their relatives were normal. For instance, a Malay carer who was a stepmother explained that her stepdaughter was not mentally ill but pretended to be ill to get attention from her husband. Another Malay carer also disagreed when her daughter was diagnosed with mental illness and presumed it was an illness due to her daughter's permanent disability, which prevented her from walking.

\subsection{Identification of Illness}

When carers initially observed their relatives' strange behaviour, they felt stressed and seek help. One of the prominent effects of mental illness recounted by caregivers was the school drop-out as some carers mentioned earlier that their relatives had been sick at a young age. For example:

"He was a normal child before, it was only when he turned 15-years-old that he started to show odd behaviour, all of a sudden, he became quiet, anti-social and too lazy to go to school. He totally changed. At that time, I had no choice; I stopped him from going to school and took him for treatment in the hospital."

It was noted that some of the carers were upset when their relatives were unable to continue studying but still had hopes for their relatives' future. Due to the mental illness, most of the carers did not expect them to work or study. However, they expected them to work or study when their condition improves and when they are mentally stable. In the meantime, they were obliged to support and care for their relatives.

\subsection{Coping Strategies}

Religious and cultural beliefs and practice are well accepted coping strategies for most caregivers in this study. Cultural beliefs coping is an important strategy for managing the cultural issues associated with mental illness as asserted by the caregivers. In line with Lazarus and Folkman (1984), the way of beliefs and knowledge might influence the way of coping with stressful life situations, as shown in the interaction between the person and the environment

\subsubsection{Religious and Spiritual Approach}

Most carers speak broadly of their religious and spiritual approaches as their coping strategies in handling their relatives with mental illness. Many of the caregivers stressed the importance of religion as a way of life. Correspondingly, carers sought religious support to cope with their stressful life. Some of them had strong belief concerning spiritual healing, especially when dealing with mental illness. For example, a mother who believed in spiritual coping stated that her children's spirits will be restored to fight the mental illness when using special media that contained spiritual power such as air-penawar (holy water). Another mother commented that the air-penawar was used to boost her relative's confidence for short period of time along with medical treatment. She claimed that "it's only temporary and does not last forever. So I use it together with the prescribed medication from the doctor."

It was noted that the air-penawar was supposed to contain spiritual powers to control the relatives 'personality disorder'. Some carers used spiritual healing to treat their relatives because it was an easy and available resource in their community, especially when they were unable to access the mental health community services. The Islamic traditional practitioner has been a popular form of alternative medicine for many generations in their relatives' illness, and was found to be effective. Most of the Muslim carers believed that Allah will help them throughout their life, both good and bad. For instance, a brother explained that he always prayed and worshipped Allah so that Allah will grant his prayers. He hoped that "by glorifying Allah continuously, his doa will be granted."

Likewise, some Chinese carers expressed that they used religious coping to deal with the relatives' illness and their own problems. Some of the Chinese carers who were Buddhists assumed that their relatives were living with mental illness due to the impurity of their soul. Therefore, they brought their relatives to the temple and worship Buddha in hope for recovery. Another Chinese carer who was a Christian noted that he regarded the church as a good place for him to provide therapy for his relative through socialising with other members of the church.

A Hindu believer recounted that spiritual healing in the Hindu temple can enhance her son's good health:

"I used to go to India to treat him. We went to the famous Hindu temple in Gujarat. When we went there, we did pooja [a Hindu prayer to God] and followed all the rituals conducted by the Swami [is primarily a Hindu honorific title for either male or female swami's]. I believed that the healing process would be more suitable in such an environment. However, before we finished three poojas he already ran away from the temple. Then the treatment became unsuccessful." 
Most of the caregivers used religious approaches to cope and manage their relatives' illness and also their own problems. Each ethnic group has their own way of coping using religious and spiritual approaches, depending strongly on their belief system. Caregivers who placed a strong believe in their religious approaches seemed to be more positive in their care giving. This is because religion is believed to promote positive energy in human beings. People who used religious coping method tended to be have higher endurance and tolerance when facing tough and stressful situations. In this way they appeared calmer, thus improved their coping skills. Koole (2010) stated that religious coping style might promote better health because religious believers managed to control their behaviour when responding to any influential situations such as a life threatening event. Pargament et al. (2005) stated that religious and spiritual coping influenced psychological distress and promoted good health. Therefore, caregivers who applied religious coping strategies might transform their stress in positive ways, which might reduce or buffer the psychological distress of care giving.

\subsubsection{Traditional Healers}

Some carers demonstrated that they seek traditional healers in the community setting in managing their relative's with mental illness. They believed that traditional healing was not limited to utilising therapeutic, physical means or prescribing a dose of medicine or herbs, but that it was a holistic approach that catered for the spiritual and psychological needs of their relatives, together with other modes of treatment. Commonly, a traditional healing system was regarded as alternative medicine. A folk medicine practitioner in Malaysia is called a bomoh, dukun, or pawang who practises alternative medicine such as the therapeutic usage of herbs, metals and animal parts. It has been noted that the traditional healers, especially the elders who are called toks, are treated with great respect, particularly in rural societies. For instance, a Malay father disclosed that he sought a bomoh when he first noticed his son's illness as a way of coping with mental illness:

"In the early years when he became sick, he started to talk to himself and refused to talk to anyone in the house. It made me worried and so I took him to the bomoh. The bomoh told me that he had been possessed by a ghost when he got near the river."

The traditional help seeking course of action is a kind of trial and error to find an effective way to treat the relative's mental illness. During this process, carers usually depended on the intermediate community resources that were available. Some of the carers tried other alternative treatments as recommended by people in their support networks. For instance, another Malay carer who was a mother also confessed that she used a bomoh, initially because she thought the mental illness was caused by possession of evil spirit and that she had been influenced by her friends to use alternative treatment. It is also noted that some of the carers were not fully satisfied with the traditional treatment. They recalled their experience of traditional healing as bomoh-shopping (kind of shopping around) as their coping strategy to search for better traditional healers. Therefore, some of the carers might use both treatments, in which the alternative medicine was regarded as complementary to the modern medicine. However, those who found that the traditional treatments failed would rely on the mental health services for treating their relatives.

One of the mothers reported that she faced difficulty in using the medical treatment for her daughter's mental illness. This was because of the conflict of interest with her husband. She mentioned the disagreement between using the mental health services and the traditional treatment. In some situations, the carers used traditional healing because of the influence of other family members who believed in traditional treatments, especially to treat illnesses surrounded by superstition as in the case of schizophrenia. For example, one Malay carer who was a husband to a mentally ill wife claimed that his family-in-laws wanted to treat his wife using traditional healing because they thought this mental illness was Saka (the superstitious belief among Malay families about the bad spirit possession) and he accepted it without question as long as it did not harm his wife.

On the other hand, an Indian sister described that she practiced alternative ayurvedic medicine by herself to treat her sister's illness while staying at home:

"I used to do ayurvedic treatment for her at home, especially when she complains of having a headache or stress. I used herbs in the form of oil, balms and liquids as herbal remedy to be massaged into her. I believe that herbal remedies will improve her blood circulation and relieve her pain and discomfort."

Some of the carers recounted that the traditional healers used different treatments to cure their relatives' mental illness. They mentioned that the bomohs used authentic sources as the spiritual therapy. For example, a father reported that the bomoh cast a magic spell on a stone and performed a massage therapy for treating his son's mental illness. He described that "the stone has a magic spell that can restore her spirit." 


\section{Discussion}

We know very little about how family caregivers' acquired knowledge and beliefs about mental health in Malaysia. It became clear through this study that they learnt through their experiences of caring a person with mental illness. This is similar to Wolff et al. (1996) study where $33 \%$ of participants in their study noted that personal experience with someone who was being diagnosed of having a mental disorder was the main source of mental health information. In this study, most of the caregivers learnt about mental health when they played the role of the main caregiver to their mentally ill relatives. They knew about the relatives' clinical manifestation and causes and effects of mental illness. They learnt and managed to cope with their caring roles after being a family caregiver for a while.

Family caregivers in this study demonstrated their attitudes that facilitated recognition of mental health and help-seeking behaviour. The coping strategies that they adopted were based on their beliefs about mental illness. Some of the carers utilised religious coping or traditional healing besides receiving medical treatment after being discharged from hospitals. Most of the caregivers who used the traditional treatments were Malay and the majority lived in the rural area. They relied very much on their cultural beliefs approaches and the resources available in their community in treating mental illness. It demonstrated the cultural beliefs approaches for coping with mental illness and because of the limited mental health services found in the rural areas, caregivers optimised other alternative treatments to help them cope with mental illness. Generally, caregivers who lived in the urban area were more exposed to other mental health services that provided them with various choices in treating their mentally ill relatives. The differences of coping strategies between caregivers in the urban and rural areas showed the different level of mental health literacy.

Some of the Malay carers in this present study affirmed that they were optimistic about the traditional treatments because of their positive attitude to keep searching for the best healers and used it to complement the mental health services. However, some of the carers disagreed with the traditional treatments and only believed in the treatment provided by mental health services. Nevertheless, caregivers have their own right to choose what treatment suited their preferences in treating their relatives. It was found through this study that most caregivers tried various treatments before deciding on the most reliable treatment for their relatives. This is an important experience in ways of coping based on their cultural beliefs. Caregivers made judgements concerning their support systems that were found to be convenient and reliable in their environment.

Generally, most of the caregivers, especially Malays, used religious or traditional coping to cope with their stressors. One of the possible explanations was related to the caregiver beliefs and the level of mental health literacy. As demonstrated in this study, most of the families of the people with mental illness in Malaysia have low mental health literacy. Because they did not understand about mental illness, they tended to treat mental health service users and their families negatively. Therefore, most of the family caregivers preferred to treat their relative's illness with secrecy, especially in the early stage. They usually used traditional healers like ustaz or bomoh or medication from the temple to heal their relative's mental illness. When they found that their traditional treatment was not effective only then they seek medical treatment. However, traditional healing as a complement to modern treatment remains a common choice of practice in Malaysia. To date, not many researchers have conducted such study in Malaysia to explore the potential roles of alternative treatment for people with mental illness particularly schizophrenia. Therefore, more studies need to be conducted in this field before making any suggestions to policy makers and practitioners when dealing with the issue of family caregivers in Malaysia.

\section{Conclusion}

This study has brought to the public awareness and understanding that the family caregiver's mental health literacy is on the average level while the public have poor mental health literacy. There are a number of strategies that can be taken as efforts to improve public knowledge of mental health. One is an awareness campaign targeted at the general population. This campaign should be aimed to provide information; recognition and treatment to inform the public and family members that mental health are common and treatable. Besides that, media involvement is also needed to educate and promote mental health through television, radio and posters as well as any print advertisement. The media publicity is an important tool to create awareness among the public about symptoms and treatments and to identify individuals who may be ignorant that they are clinically depressed, and or presenting symptoms of schizophrenia. In Malaysia there is the Malaysian Mental Health Association (MMHA) who runs the awareness campaign that aims to educate the public about mental health and its treatment and to reduce the stigma towards mentally ill patients. However, mental health professionals in Malaysia face and confront disbelief and misunderstanding about mental illness that are bound 
in the culture. The complexity of different ethnic beliefs poses some challenges to mental health professionals. Another strategy that can be done is to promote an early help-seeking behaviour by encouraging the public and families to have partnership with health care providers, educators and treatment centres. All of these strategies need to be implemented with the commitment from government, private and non-government agencies as an agenda to develop a 'mental health literate' society.

\section{References}

Addis, M. E., \& Jacobson, N. S. (1996). Reasons for depression and the process and outcome of cognitive-behavioural psychotherapies. Journal of Consulting and Clinical Psychology, 64(6), 1417-1424. http://dx.doi.org/10.1037/0022-006X.64.6.1417

Angermeyer, M. C., \& Matschinger, H. (1996a). Relatives' beliefs about the causes of schizophrenia. Acta Psychiatrica Scandinavica, 93(3), 199-204. http://dx.doi.org/10.1111/j.1600-0447.1996.tb10632.x

Angermeyer, M. C., \& Matschinger, H. (1996b). The effect of diagnostic labeling on the lay theory regarding schizophrenic disorders. Social Psychiatry and Psychiatric Epidemiology, 31(6), 316-320. http://dx.doi.org/10.1007/BF00783419

Angermeyer, M. C., Breier, P., Dietrich, S., Kenzine, D., \& Matschinger, H. (2005). Public attitudes toward psychiatric treatment. Social Psychiatry and Psychiatric Epidemiology, 40(11), 855-64. http://dx.doi.org/10.1007/s00127-005-0958-x

Angermeyer, M. C., Matschinger, H., \& Riedel-Heller, S. G. (1999). Whom to ask for help in case of mental disorder? Social Psychiatry and Psychiatric Epidemiology, 34(4), 202-210. http://dx.doi.org/10.1007/s001270050134

Barriball, K. L., \& While, A. (1994). Collecting data using a semi-structured interview. Journal of Advanced Nursing, 19(2), 328-335. http://dx.doi.org/10.1111/j.1365-2648.1994.tb01088.x

Brandli, H. (1999). The image of mental illness in Switzerland. In Guimon, J., Fischer, W. \& Sartorius, N. (Eds.), The image of madness: The public facing mental illness and psychiatric treatment. Basel: Karger.

Cohen, A., Kleinman, A., \& Saraceno, B. (2002). World mental health casebook: Social and mental health programs in low-income countries. New York: Kluwer Academic/ Plenum.

DeWalt, D. A., Berkman, N. D., Sheridan, S., Lohr, K. N., \& Pigone, M. P. (2004). Literacy and health outcomes: A systematic review of the literature. Journal of General Internal Medicine, 19(12), 1228-1239. http://dx.doi.org/10.1111/j.1525-1497.2004.40153.x

Dietrich, S., Beck, M., Bujantugs, B., Kenzine, D., Matschinger, H., \& Angermeyer, M. C. (2004). The relationship between public causal beliefs and social distance toward mentally ill people. Australian and New Zealand Journal of Psychiatry, 38(5), 348-354. http://dx.doi.org/10.1111/j.1440-1614.2004.01363.x

Furnham, A., Abajian, N., \& McClelland, A. (2011). Psychiatric literacy and personality disorders. Psychiatry Research, 189(1), 110-114. http://dx.doi.org/10.1016/j.psychres.2011.02.024

Ganasen, K. A., Parker, S., Hugo, C. J., Stein, D. J., Emsley, R. A., \& Seedat, S. (2008). Mental health literacy: focus on developing countries. African Journal of Psychiatry, 11(1), 23-28.

Jorm, A. F. (2000). Mental health literacy: Public knowledge and beliefs about mental disorders. The British Journal of Psychiatry, 177(5), 396-401. http://dx.doi.org/10.1192/bjp.177.5.396

Jorm, A. F., Korten, A. E., Jacomb, P. A., Christensen, H., Rodgers, B., \& Pollitt, P. (1997). Mental health literacy: A survey of the public's ability to recognise mental disorders and their beliefs about the effectiveness of treatment. The Medical Journal of Australia, 166(4), 182-186.

Koole, S. L., Roelofsma, P. H. M. P., McCullough, M. E., \& Kuhl, J. (2010). Why religion's burdens are light: From religiosity to implicit self-regulation. Personality and Social Psychology Review, 14(1), 95-107. http://dx.doi.org/10.1177/1088868309351109

Lauber, C., Nordt, C., Falcato, L., \& Rossler, W. (2003). Do people recognize mental illness? Factors influencing mental health literacy. European Archives of Psychiatry and Clinical Neuroscience, 253(5), 248-251. http://dx.doi.org/10.1007/s00406-003-0439-0

Lazarus, R. S., \& Folkman, S. (1984). Stress, appraisal, and coping. Springer Publications. 
Link, B. G., Phelan, J. C., Bresnahan, M., Stueve, A., \& Pescosolido, B. A. (1999). Public conceptions of mental illness: Labels, causes, dangerousness, and social distance. American Journal of Public Health, 89(9), 13-28. http://dx.doi.org/10.2105/AJPH.89.9.1328

Matschinger, H., \& Angermeyer, M. C. (1996). Lay beliefs about the causes of mental disorders: A new methodological approach. Social Psychiatry and Psychiatric Epidemiology, 31(6), 309-315. http://dx.doi.org/10.1016/j.psychres.2006.05.002,

Nutbeam, D., \& Kickbusch, I. (2000). Advancing health literacy: A global challenge for the 21st century. Health Promotion International, 15(3), 183-184. http://dx.doi.org/10.1093/heapro/15.3.183

Pargament, K. I., Magyar-Russell, G. M., \& Murray-Swank, N. A. (2005). The sacred and the search for significance: Religion as a unique process. Journal of Social Issues, 61(4), 665-687. http://dx.doi.org/10.1111/j.1540-4560.2005.00426.x

Razali, S. M., \& Yassin, A. M. (2008). Complementary treatment of psychotic and epileptic patients in Malaysia. Transcultural Psychiatry, 45(3), 455-469. http://dx.doi.org/10.1177/1363461508094676

Razali, S. M., Khan, U. A., \& Hasanah, C. I. (1996). Belief in supernatural causes of mental illness among $\begin{array}{lllll}\text { Malay patients. } \quad \text { Acta } & \text { Psychiatrica } 2233 .\end{array}$ http://dx.doi.org/10.1111/j.1600-0447.1996.tb09854.x

Ritchie, J., \& Lewis, J. (2003). Qualitative research practice: A guide for social science students and researchers. London: Sage Publications.

Wolff, G., Pathare, S., Craig, T., \& Leff, J. (1996). Community knowledge of mental illness and reaction to mentally ill people. The British Journal of Psychiatry, 168(2), 191-198. http://dx.doi.org/10.1192/bjp.168.2.191 